\title{
Long term and disease-free survival following surgical resection of occult N2 lung cancer
}

\author{
Bilal H. Kirmani ${ }^{1,2}$, Sara Volpi ${ }^{1}$, Giuseppe Aresu ${ }^{1}$, Adam Peryt ${ }^{1}$, Thida Win ${ }^{3}$, Aman S. Coonar ${ }^{1,3}$ \\ ${ }^{1}$ Thoracic Surgery, Royal Papworth Hospital, Cambridge, UK; ${ }^{2}$ Cardiothoracic Surgery, Liverpool Heart and Chest Hospital, Liverpool, UK; \\ ${ }^{3}$ Respiratory Medicine \& Thoracic Oncology, Lister Hospital, Stevenage, UK \\ Contributions: (I) Conception and design: BH Kirmani, AS Coonar; (II) Administrative support: AS Coonar, G Aresu, A Peryt; (III) Provision of \\ study materials or patients: BH Kirmani, S Volpi, AS Coonar; (IV) Collection and assembly of data: BH Kirmani, S Volpi; (V) Data analysis and \\ interpretation: BH Kirmani, S Volpi, T Win; (VI) Manuscript writing: All authors; (VII) Final approval of manuscript: All authors. \\ Correspondence to: Bilal H. Kirman. Cardiothoracic Surgery, Liverpool Heart and Chest Hospital, Liverpool L14 3PE, UK. \\ Email: bilal.kirmani@lhch.nhs.uk
}

Background: Despite systematic investigation with computed tomography (CT), positron emission tomography (PET)/CT, CT or magnetic resonance imaging (MRI) brain imaging and supplementary investigation using endobronchial ultrasound guided biopsy (EBUS), endo-oesophageal ultrasound guided biopsy (EUS), fine needle aspiration (FNA), mediastinoscopy or mediastinotomy, there is an approximately $10 \%$ rate of occult N2 disease identified at pathological staging. It has been hypothesised that such occult disease, too small or inactive to be identified during pre-operative multi-modality staging, may represent low volume disease that may have equivalent survival to patients with similar stage at clinical, pre-operative assessment. We compared the long-term survival and disease-free survival of patients with the same clinical TNM stage with and without occult N2 disease.

Methods: We retrospectively analysed a database that prospectively captured information on all patients assessed and treated for lung cancer in our surgical unit. We reviewed data on patients who underwent lung cancer surgery with curative intent between January 2006 and August 2010.

Results: A total of 312 lung cancer resections were performed [mean age 68 (range, 42-86) years old and male:female ratio 1.14:1]. Occult N2 disease was identified in 28 (8.7\%) of 312 patients. There was no difference in the rate of $\mathrm{N} 2$ disease for different tumour histological types. Five-year survival with occult N2 disease was $35.8 \%$ vs. $62.5 \%$ without. Median survival was 34 months with occult N2 disease vs. 84 months without.

Conclusions: With contemporary staging techniques, so-called occult N2 disease, even with low volume and PET non-avid disease, does not have an indolent course and should still be considered a risk factor for poorer prognosis.

Keywords: Carcinoma; non-small cell lung cancer staging (NSCLC staging); metastasis; surgical procedures, operative

Submitted Mar 13, 2018. Accepted for publication Jun 19, 2018.

doi: $10.21037 /$ jtd.2018.07.125

View this article at: http://dx.doi.org/10.21037/jtd.2018.07.125

\section{Introduction}

Technological advances are considered to have led to improved lung cancer staging. In particular, cross-sectional imaging with better resolution and thinner slices, combined with positron emission tomography (PET) have allowed increasingly small volume metastases to be identified during pre-operative staging. Combined with modern multi-modal techniques of lymph node sampling including endobronchial ultrasound guided biopsy (EBUS), endooesophageal ultrasound guided biopsy (EUS) and surgical 
mediastinal lymph node sampling, it was thought that this would lead to a reduction in the incidence of unexpected N2 disease identified at the time of surgical resection. Recent studies have demonstrated however that this remains at around $10 \%$ (1).

Occult pathological N2 disease had previously been noted to have a better prognosis than lung cancers that were known to have metastasised (2), but much of the research predated the advent of the modern staging and treatment processes.

We therefore sought to identify if low-volume, PET non-avid metastatic disease that had evaded systematic modern multi-modal screening for nodal spread was associated with outcomes similar to that of non-metastatic disease.

\section{Methods}

\section{Population}

The study population has been previously described in our paper outlining the rates of stage migration following multimodal staging (1). The institutional review board of the hospital waived the need for ethical approval or individual patient consent as all patient data was anonymised and unidentifiable. All patients assessed and treated for lung cancer in our tertiary referral centre from January 2006 to August 2010 were included in this study. Inclusion criteria were: all patients undergoing curative surgical resection of suspected or confirmed primary lung cancer. Exclusion criteria included: administration of neo-adjuvant chemotherapy, pathological finding of non-primary lung cancer, "open-and-shut" thoracotomy for unresectable disease and tumours other than non-small cell lung cancers (NSCLC). Follow-up data for survival were censored at February 2017.

\section{Clinical assessment}

All patients were discussed at pre-operative multidisciplinary team meetings following thoracic and upper abdominal computed tomography (CT) and synchronised CT with ${ }^{18}$ FDG positron emission tomography (CTPET). Brain imaging, with CT or magnetic resonance imaging (MRI), was also usually performed. Lymph node involvement by radiological criteria ( $>10 \mathrm{~mm}$ in short axis); or with a maximum standardised uptake value (SUV) of more than 2.0 led to invasive staging for confirmation of nodal status. Tests included:

* Fine needle aspiration (FNA) or core biopsy (usually ultrasound guided);

* EBUS/EUS and FNA;

* Mediastinoscopy or mediastinotomy;

* Bronchoscopy;

* Video-assisted thoracoscopic surgery (VATS);

* Thoracotomy;

* Biopsy of other sites where indicated.

The clinical stage (cTNM), was determined by the multidisciplinary team after all radiological, minimally invasive and surgical staging tests had been completed; pathological staging (pTNM) was established from surgical findings and post-operative histology results. The distribution of clinical and pathological stages was based on the International Union Against Cancer (UICC) TNM classification in use at the time (6th edition).

\section{Analysis}

Data were analysed using R version 3.3.3 for Mac (3). Demographic data was analysed using Wilcoxon signed rank test for continuous variables and $\chi^{2}$ for categorical data. Survival data was assessed by review of Kaplan-Meier curves and log-rank test for unadjusted data; and by Coxregression analysis following full covariate adjustment.

\section{Results}

\section{Demographics}

A total of 377 patients met the inclusion criteria. Sixtyfive patients were excluded for benign disease (13 patients), unresectable disease (17 patients, including 11 undergoing exploratory thoracotomy) and non-NSCLC (35 patients). Of the remaining 312 patients, 61 (19.6\%) required invasive lymph node staging and were deemed to be suitable for surgical resection with curative intent. Some tumours contained mixed histology. The demographic details, stratified by post-operative nodal status are shown in Table 1 . There were no significant differences in the patient profiles.

\section{Surgery}

A total of 312 surgical resections were performed of which 247 (79\%) were lobectomies, 49 (16\%) pneumonectomies and $15(5 \%)$ segmentectomies. During surgery, lymph node samples were taken from as many mediastinal stations as 
Table 1 Pre-operative profiles of patients by N-status

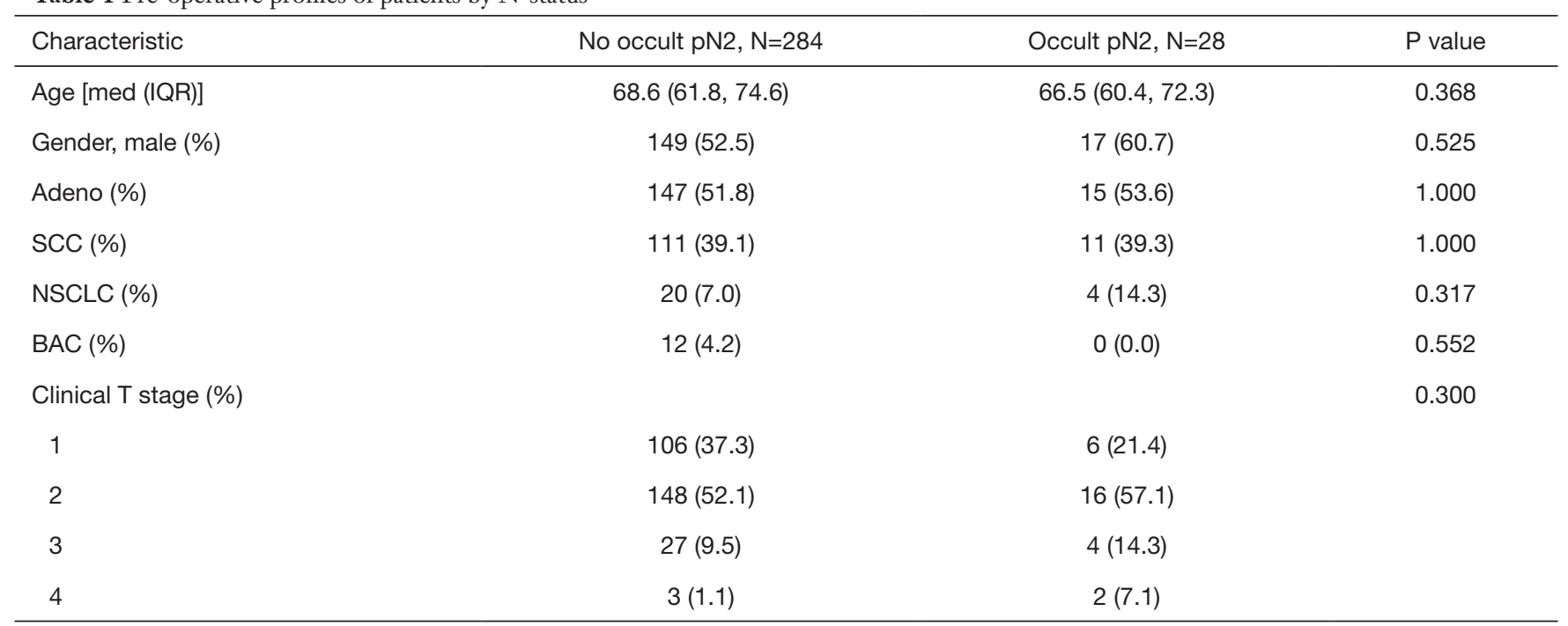

Med, median; IQR, interquartile range; Adeno, adenocarcinoma excluding bronchoalveolar carcinoma; SCC, squamous cell carcinoma; NSCLC, non-small cell lung cancer; BAC, bronchoalveolar carcinoma.

possible, with emphasis placed on zones proximal to the tumour. Station 7 was dissected in all cases.

From histology, 162 adenocarcinomas, 122 squamous cell carcinomas, 12 broncho-alveolar carcinomas and 24 unspecified non-small cell cancers were identified. More than one tumour type were identified in 7 patients. Occult $\mathrm{N} 2$ disease was detected at the time of surgery in $9.0 \%$. This was single-station in 20 patients $(71.4 \%)$ and multistation in 8 patients $(28.6 \%)$.

\section{$N$-status migration by histology}

Newly identified N2 disease predominantly comprised small or microscopic deposits (in 23 of 28 patients). The remainder of cases had nodes completely replaced by tumour, but histology was not significantly different between microscopic and macroscopic groups $(\mathrm{P}=0.68)$. There was no statistically significant effect of histological subgroup on nodal status migration $(\mathrm{P}=0.28)$.

\section{Survival, recurrence and disease-free survival by $\mathrm{N}$-status}

There was a statistically significant difference in overall survival in patients with occult $\mathrm{pN} 2$ disease compared to patients without occult $\mathrm{pN} 2$ disease (median survival 33.8 vs. 80.5 months, $\mathrm{P}=0.0044$ ) as demonstrated in Figure 1. Disease-free survival was also reduced in occult $\mathrm{pN} 2$ disease
(105 vs. 127 months, $\mathrm{P}=0.049)$ (Figure 2). The time to recurrence in occult $\mathrm{pN} 2$ disease was also shorter (24.9 vs. 68.2 months, $\mathrm{P}=0.00065$ ) (Figure 3).

A Cox-regression analysis was performed using age, gender, histology, pre-operative stage, modes of lymph node testing utilised, nodal stations and occult $\mathrm{pN} 2$ status. Adjusted for these clinical risk factors, the hazard ratio for death or recurrence with occult $\mathrm{pN} 2$ disease was found to be 2.26 [95\% confidence interval (CI), 1.37-3.73, $\mathrm{P}=0.0015]$. Unadjusted, the hazard ratio was 1.89 ( $95 \% \mathrm{CI}$, 1.21-2.96, $\mathrm{P}=0.0051$ ).

\section{Discussion}

Current guidelines on the investigation of suspected lung cancer advise the use of staging CT, integrated CTPET and invasive evaluation where necessary (4-6). We previously found that despite such modern practice in lung cancer staging, there was a substantial rate of stage migration between clinical and pathological staging (1). At the time we were unclear on the prognostic significance of this newly identified low volume PET non-avid nodal disease. Specifically, we speculated that the prognosis may be more favourable than then normally associated with N2 disease. This follow-up study demonstrates that this disease does confer the poorer prognosis associated with $\mathrm{N} 2$ disease. 


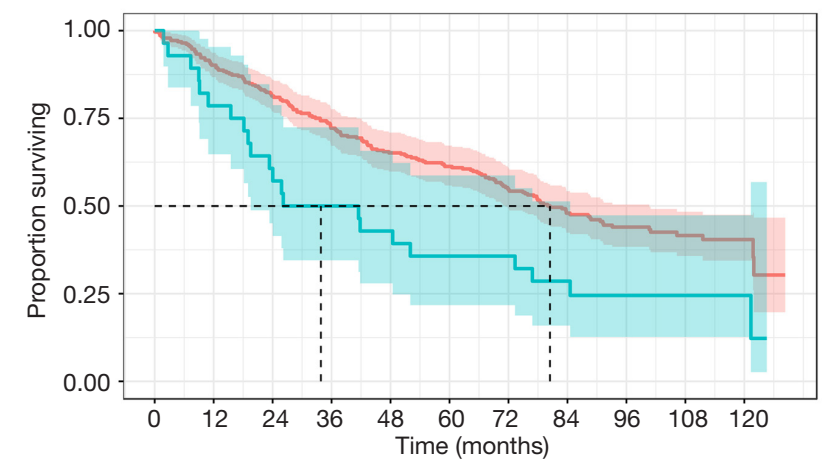

Number at risk

$\begin{array}{llllllllllll}\text { No Occult N2 } & 284 & 256 & 231 & 205 & 185 & 174 & 156 & 112 & 76 & 42 & 17\end{array}$

$\begin{array}{llllllllllll}\text { Occult N2 } & 28 & 22 & 17 & 14 & 12 & 10 & 10 & 7 & 4 & 4 & 2\end{array}$

Figure 1 Kaplan-Meier curve of survival by pN2 status.

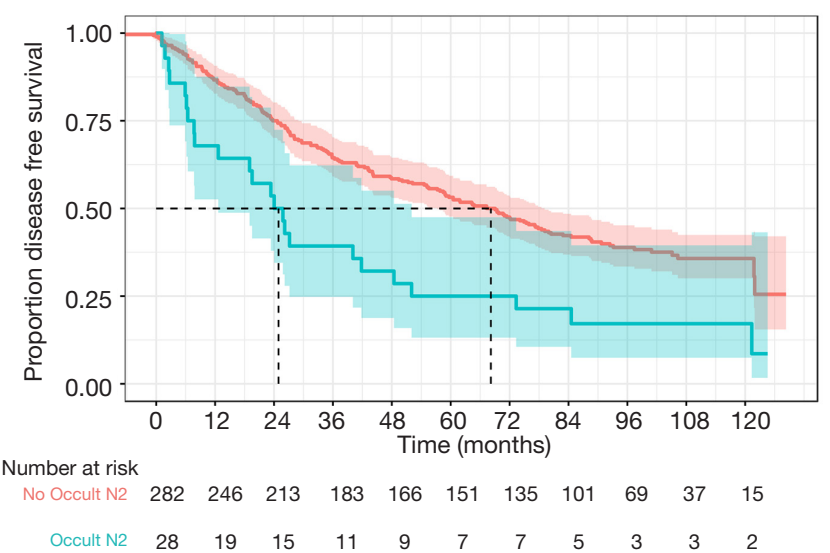

Figure 2 Kaplan-Meier curve of disease free survival by pN2 status.

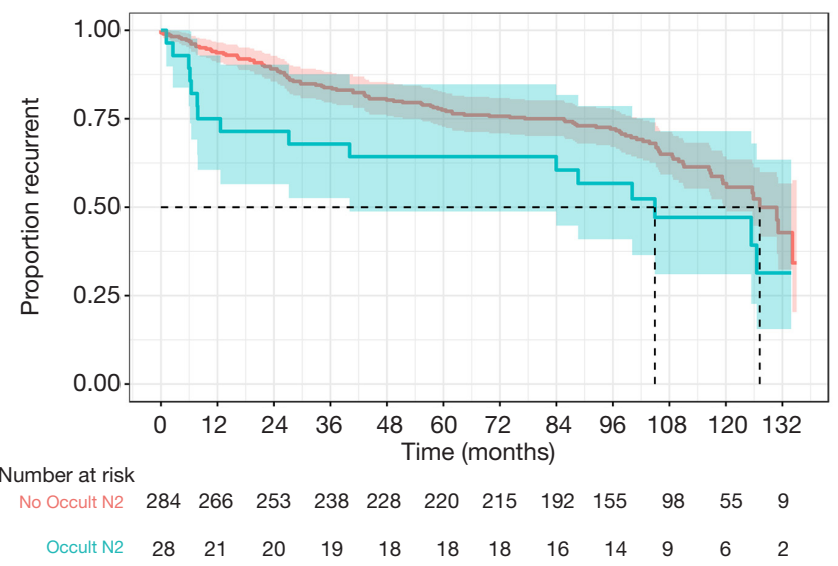

Figure 3 Kaplan-Meier curve of recurrence by pN2 status.
Occult N2 disease identified following negative mediastinoscopy confers a survival advantage over N2 disease discovered pre-operatively and denied surgery (2). De Leyn et al. found that 5 -year survival in patients with occult pN2 disease was $22 \%$ (7). This finding was corroborated by Nakanishi, who also found similar survival rates (8). Both researchers also found that extent of N2 disease was not associated with reduced survival. The Leuven Lung Cancer Group found that there was increased risk with multi-level N2 disease (relative risk 1.68) but demonstrated equivalent survival rates (9). Tanaka and Cerfolio also both found diminishing survival with increasing number of involved lymph node stations (10,11). Kang et al. found that by multivariable regression modelling, multiple lymph node involvement but not occult N2 disease were negative prognostic factors (12).

Decaluwé et al. found that single station N2 disease identified pre-operatively, and multi-level cN2 disease that was downstaged following induction chemotherapy had more favourable outcomes (13). It has previously been demonstrated that microscopic disease may also confer a survival advantage over more overt $\mathrm{N} 2$ disease comparable to N1 disease (14).

Higher rates of mediastinal lymph node dissection may reveal a greater incidence of $\mathrm{pN} 2$ disease than previously known (15). The effect of this may be higher uptake of adjuvant chemotherapy. The survival effect of this, however, is not appreciated at present. For patients undergoing modern evaluation, the burden of disease present that is undetectable by multi-modal staging perhaps represents such smaller volume metastases. This may have the same outcome as $\mathrm{pN} 1$ disease (16).

The finding of $\mathrm{pN} 2$ disease at the time of resection has been previously found to be associated with a better prognosis than $\mathrm{cN} 2$ disease excluded from surgery (4-6). Pre-operative staging techniques rely on radiological identification of suspicious lymph nodes for biopsy, and SUV levels are correlated with outcome (17).

It is likely that advances in imaging technology will make only small incremental improvements to the identification of lymph nodes for biopsy prior to radical treatment for lung cancer. There will, therefore, continue to be a proportion of patients who undergo resection and are found after surgery to have $\mathrm{pN} 2$ disease. As compared to patients with $\mathrm{N} 0 / 1$ disease, these patients have a poorer outlook, despite adjuvant chemotherapy, but equivalent survival to patients with stage IIIA lung cancer in general $[19 \%$ clinical or $24 \%$ pathologic stage IIIA in the 2007 lung cancer 
staging project (18)].

It was not known whether the effects of multi-modal staging including high-resolution imaging, EBUS, EUS and surgical staging techniques might identify pre-operatively lower volume $\mathrm{cN} 2$ disease. It was our hypothesis that patients with occult disease in this era might have some survival benefit over historic patients in whom less stringent clinical staging would allow patients with macro-metastatic disease to proceed to surgery. Thus far, we have been unable to demonstrate a survival advantage to this cohort of patients despite improved technologies for diagnosis. Whilst this should not alter the diagnostic or therapeutic approach, it may provide useful data for counselling patients who are diagnosed post-operatively with new pN2 disease.

\section{Limitations}

This was a retrospective, pragmatic and single centre study with all the associated limitations of this design. Without true trial standardisation, variations in practice will have led to operator-dependent results for pre-operative staging and intra-operative nodal clearance.

\section{Conclusions}

Despite systematic intensive radiological and invasive staging, a proportion of patients will be found to have occult pN2 disease. Despite low-volume or PET negative disease these patients have a poorer prognosis.

\section{Acknowledgements}

None.

\section{Footnote}

Conflicts of Interest: Initial data presented at Society for Cardio-Thoracic Surgery in Great Britain and Ireland Annual Conference, Belfast, Northern Ireland 12-14 March 2017.

Ethical Statement: The institutional review board of the hospital waived the need for ethical approval or individual patient consent as all patient data was anonymised and unidentifiable.

Disclaimer: This data includes some patients who were recruited into the multi-centre ASTER study.

\section{References}

1. Kirmani BH, Rintoul RC, Win T, et al. Stage migration: results of lymph node dissection in the era of modern imaging and invasive staging for lung cancer. Eur J Cardiothorac Surg 2013;43:104-9; discussion 109-10.

2. van Klaveren RJ, Festen J, Otten HJ, et al. Prognosis of unsuspected but completely resectable N2 non-small cell lung cancer. Ann Thorac Surg 1993;56:300-4.

3. R Foundation for Statistical Computing, Vienna, Austria. Available online: http://www.R-project.org

4. Goldstraw P, Mannam GC, Kaplan DK, et al. Surgical management of non-small-cell lung cancer with ipsilateral mediastinal node metastasis (N2 disease). J Thorac Cardiovasc Surg 1994;107:19-27; discussion 27-8.

5. Robinson LA, Ruckdeschel JC, Wagner H Jr, et al. Treatment of non-small cell lung cancer-stage IIIA: ACCP evidence-based clinical practice guidelines (2nd edition). Chest 2007;132:243S-65S.

6. Andre F, Grunenwald D, Pignon JP, et al. Survival of patients with resected $\mathrm{N} 2$ non-small-cell lung cancer: evidence for a subclassification and implications. J Clin Oncol 2000;18:2981-9.

7. De Leyn P, Schoonooghe P, Deneffe G, et al. Surgery for non-small cell lung cancer with unsuspected metastasis to ipsilateral mediastinal or subcarinal nodes (N2 disease). Eur J Cardiothorac Surg 1996;10:649-54.

8. Nakanishi R, Osaki T, Nakanishi K, et al. Treatment strategy for patients with surgically discovered N2 stage IIIA non-small cell lung cancer. Ann Thorac Surg 1997;64:342-8.

9. Vansteenkiste JF, De Leyn PR, Deneffe GJ, et al. Survival and prognostic factors in resected N2 non-small cell lung cancer: a study of 140 cases. Leuven Lung Cancer Group. Ann Thorac Surg 1997;63:1441-50.

10. Tanaka F, Yanagihara K, Otake $Y$, et al. Prognostic factors in resected pathologic (p-) stage IIIA-N2, non-small-cell lung cancer. Ann Surg Oncol 2004;11:612-8.

11. Cerfolio RJ, Bryant AS. Survival of patients with unsuspected N2 (stage IIIA) nonsmall-cell lung cancer. Ann Thorac Surg 2008;86:362-6; discussion 366-7.

12. Kang CH, Ra YJ, Kim YT, et al. The impact of multiple metastatic nodal stations on survival in patients with resectable N1 and N2 nonsmall-cell lung cancer. Ann Thorac Surg 2008;86:1092-7.

13. Decaluwé H, De Leyn P, Vansteenkiste J, et al. Surgical multimodality treatment for baseline resectable stage IIIA-N2 non-small cell lung cancer. Degree of mediastinal 
lymph node involvement and impact on survival. Eur J

Cardiothorac Surg 2009;36:433-9.

14. Fontaine E, McShane J, Carr M, et al. Should we operate on microscopic N2 non-small cell lung cancer? Interact Cardiovasc Thorac Surg 2011;12:956-61; discussion 961.

15. Cerfolio RJ, Bryant AS, Minnich DJ. Complete thoracic mediastinal lymphadenectomy leads to a higher rate of pathologically proven N2 disease in patients with nonsmall cell lung cancer. Ann Thorac Surg 2012;94:902-6.

16. Lee DH, Kim JB, Keum DY, et al. Long term survival of patients with unsuspected N2 disease in non-small cell lung cancer. Korean J Thorac Cardiovasc Surg 2013;46:49-55.

Cite this article as: Kirmani BH, Volpi S, Aresu G, Peryt A, Win T, Coonar AS. Long term and disease-free survival following surgical resection of occult N2 lung cancer. J Thorac Dis 2018;10(8):4806-4811. doi: 10.21037/jtd.2018.07.125
17. Paesmans M, Berghmans T, Dusart M, et al. Primary tumor standardized uptake value measured on fluorodeoxyglucose positron emission tomography is of prognostic value for survival in non-small cell lung cancer: update of a systematic review and meta-analysis by the European Lung Cancer Working Party for the International Association for the Study of Lung Cancer Staging Project. J Thorac Oncol 2010;5:612-9.

18. Goldstraw P, Crowley J, Chansky K, et al. The IASLC Lung Cancer Staging Project: proposals for the revision of the TNM stage groupings in the forthcoming (seventh) edition of the TNM Classification of malignant tumours. J Thorac Oncol 2007;2:706-14. 